\title{
Impact of Information and Communication Technology on Social Capital in Aboriginal Communities in Canada
}

\author{
Javier Mignone and Heather Henley \\ Faculty of Human Ecology, University of Manitoba, \\ Winnipeg, MB, Canada
}

\section{mignonej@cc.umanitoba.ca; henley2@cc.umanitoba.ca}

\begin{abstract}
This article examines the potential impact of information and communication technology on social capital in First Nations, Inuit and Métis communities. The analysis led to the conclusion that both the "what" and the "how" of connectivity matter. Policy and research priority issues are also discussed.
\end{abstract}

Keywords: information communication technology, connectivity, Aboriginal, broadband networks, community networks, social capital.

\section{Introduction}

In Canada, the last several years have seen a significant growth in information and communication technology (ICT) opportunities, particularly in relation to online capabilities. A diverse number of Aboriginal communities have been part of this process. There are numerous experiences where the growth in ICT appears to be having an important impact on socioeconomic realities.

Scholars suggest that community ICT networks provide greater access to essential services such as education, training, and health care (Fawcett, Francisco, \& Schultz, 2000) and may increase community capacity, ultimately strengthening communities (Telenor, 2004). Increased access to information is reported to improve a community's ability to interact with other organizations, such as governments, businesses, and other administrative units. These capabilities would enable more equitable participation in areas of community administration and governance (Daly, 2005). A U.S. study (Ruiz, 2004) found that broadband access is an important part of enhancing rural community development, improving the economy, health care, and general quality of life. Nonetheless, a case study on the social transformations induced by the high-speed Internet connectivity in a town of the province of New Brunswick, Canada, found very little evidence of transformation especially at the household level. While the study found many examples of new uses and ac-

Material published as part of this publication, either on-line or in print, is copyrighted by the Informing Science Institute. Permission to make digital or paper copy of part or all of these works for personal or classroom use is granted without fee provided that the copies are not made or distributed for profit or commercial advantage AND that copies 1) bear this notice in full and 2) give the full citation on the first page. It is permissible to abstract these works so long as credit is given. To copy in all other cases or to republish or to post on a server or to redistribute to lists requires specific permission and payment of a fee. Contact 0HPublisher@InformingScience.org to request redistribution permission. tivities as a result of broadband adoption, there were few examples of a change in behaviours, attitudes, relationships, and operating norms as a result (Selouani \& Hamam, 2007).

In recent years, social capital (tentatively defined as the institutions, relationships, and norms that shape the quality and quantity of society's social interactions) has become one of the relevant 
notions for measuring the impacts of ICT in communities (O'Neil, 2002). Nonetheless, there is still much that is unknown about how ICT affects community life both positively and negatively. Simultaneously, what is known as the digital divide (Norris, 2003) is still far from being bridged. This study builds on prior work by the authors on Aboriginal social capital (Mignone, 2003a, 2003b; Mignone, Longclaws, O’Neil, \& Mustard, 2004) and sought to address three questions: Can social capital be a useful notion in assessing the impact of ICT? How can ICT impact the community social capital? Does the type of ICT development matter in terms of social capital? The study questions were developed in response to interest in understanding how ICT development in Aboriginal communities in Canada can be assisted both from an implementation and impact perspective.

The article initially reviews the theory of social capital as it applies to Aboriginal peoples in Canada and presents the social capital framework that guides its examination in relation to ICT. It then presents a summary of case descriptions of ICT implementation in First Nations, Inuit and Métis communities, and one specifically related to urban settings. Using the case studies as main source of information, the article analyzes the potential impact of ICT on social capital applying the study's framework. When analyzing the potential for impact the article provides evidence of the plausibility of impact, not evidence of impact per se. The study design and the data available did not allow for the latter type of evidence. The section concludes by revisiting ICT and social capital. The final section of the article discusses policy and research priority issues.

\section{Social Capital Framework}

A common understanding amongst social scientists is that social capital is a relational resource composed of a variety of elements, most notably social networks, social norms, values, trust, and shared physical resources (Bourdieu, 1983; Bourdieu \& Wacquant, 1992; Lin, 2001; Loury, 1992; Narayan, 1999; Putnam, 2000; Putnam, Leonardi, \& Nanetti, 1993; Schuller, Baron, \& Field, 2000; Woolcock, 1998a, 1998b; Woolcock \& Narayan, 2000). The function of social capital refers to the enabling of some societal good within the boundary of that specific societal level (Coleman, 1988, 1990). Social capital is mostly considered an aggregate feature that can aid in the characterization of a social system. For Bourdieu (1983), social capital relates to actual or potential resources within a social structure that collectively support each of its members, and it is linked to the possession of a durable network of relationships of mutual acquaintance and recognition. Although the notion of social capital at a community level may share elements of what may be considered cultural aspects of a community, it is distinct in that it seeks to capture types of social investments. Nonetheless, social capital may provide a slant to the understanding of communities that overlaps with the notion of culture.

Social capital has been studied in relation to education, labour markets (Department of Economics, 1999), local economic development (Midgley \& Livermore, 1998), microfinance (Rankin, 2002), sustainable community development (Dale, 2005), economic performance (Casey \& Christ, 2005), health (Bolin, Lindgren, Lindström, \& Nystedt, 2003; Campbell, Williams, \& Gilgen, 2002; Gooden, 1998; Kawachi, Kennedy, Lochner, \& Prothrow-Stith, 1997; Rose, 2000; Veenstra, 2000), identity, transition to work (Fevre, 2000), communicative competence and human resources (Szreter, 2000), among other approaches.

More recently, studies specific to social capital and ICT have appeared. A recently published multidisciplinary volume (Huysman \& Wulf, 2004) compiles a series of articles that examine this relationship from the fields of computer science, sociology, communication, economics, and management. One of these papers (Quan-Haase \& Wellman, 2004) argues that the effects of the Internet on social capital can be conceptualized from three broad approaches. First, "the Internet transforms social capital," meaning that it leads to major transformations in social contact and civic involvement away from local and group-based solidarities and toward more spatially dis- 
persed and sparsely knit interest-based social networks (Barlow, Birkets, Kelly, \& Slouka, 1995; Wellman, Quan-Haase, Witte, \& Hampton, 2001). Second, "the Internet diminishes social capital;" through its entertainment and information capabilities it draws people away from family and friends (Nie, 2001; Nie, Hillygus, \& Erbring, 2002). Third, "the Internet supplements social capital;" as another means of communication, it facilitates existing social relationships as well as helps build patterns of civic engagement and socialization (Chen, Boase, \& Wellman, 2002; Quan-Haase \& Wellman, 2002). Among the initial studies that have specifically looked at the impact of ICT on social capital, one of them (Norris, 2003) concludes that the Internet seems to widen the experience of community, and the other (Steinmueller, 2004) that social networks are influenced by (and influence) ICTs.

It was not until the year 2000 that research concerning social capital and Aboriginal peoples picked up pace. Levitte (2004) researched social capital in the context of aboriginal economic development in Canada. Social capital has been used to analyze traditional forms of Indigenous governance (Hunter, 2000; Schwab \& Sutherland, 2001), sustainable development (Altman, 2001), welfare reform (Smith, 2001), and Indigenous learning communities (Schwab \& Sutherland, 2001). Social capital has also been used as a means to better understand the disconnect between the management of waste in nine First Nations communities in Northwest British Columbia and their traditional relationship with the land (Moody \& Cordua-von Specht, 2005).

A study by Mignone and colleagues (Mignone, 2003a, 2003b; Mognone et al., 2004) formulated a conceptual framework of social capital for First Nations communities and developed a culturally appropriate instrument for its measurement. The operational definition of social capital derived from the study was the following:

Social capital characterizes a community based on the degree that its resources are socially invested, that it presents an ethos of trust, norms of reciprocity, collective action, and participation, and that it possesses inclusive, flexible and diverse networks. Social capital of a community is assessed through a combination of its bonding (within group relations), bridging (inter-community ties), and linking (relations with formal institutions) dimensions.

Although this definition was derived from an analysis that tested broad theoretical ideas against the specific ethnographic realities of First Nations communities, we believe it is arguably relevant beyond the specific communities from which it arose. This current definition includes minor revisions post publication of papers reporting on the above mentioned study (Mignone, 2003a; Mignone et al., 2004; Mignone \& O’Neil, 2005).

Bonding social capital refers to internal community relations. It addresses the networks, ethos, and socially invested resources within a particular society, community or group in question, i.e., the intra-community ties. Bridging social capital is essentially a horizontal notion, implying connections between societies, communities, or groups, i.e., the inter-community ties. Linking social capital refers to a vertical dimension, i.e., the relations with formal institutions beyond the community. Specifically to our study, bonding social capital refers to relations within each Aboriginal community. Bridging refers to horizontal links with other communities, be they other Aboriginal communities or other communities of place (e.g., urban centres). Linking refers to connections between particular Aboriginal communities and institutions like federal/provincial government departments and public/private corporations (e.g., Indian and Northern Affairs Canada, Industry Canada, Manitoba Hydro, private ICT companies, banks).

Table 1 summarizes the social capital framework, showing each dimension as consisting of the three components and their descriptors. For socially invested resources (SIR) the descriptors are physical (e.g., building a recreation centre or paving community roads), symbolic (e.g., resources that strengthen cultural identity, like cultural camps or Aboriginal language programs), financial 
(e.g., access to credit to help people start small businesses), human (e.g., the skills, talent, experience, education, attitudes, and strengths that people bring to a community) or natural (e.g., land or water that has been protected from pollutants or degradation). Resources can be consumed or stored. The central notion is that these resources be socially invested, i.e., that they be potentially accessed by, or of potential future benefit to, any member of the community. Each descriptor captures the resource investment at a particular stage of its development. The term ethos (in the sense of character or disposition of a community) to name a component of social capital is used to capture the notions of trust (e.g., of Chief and Council, or generally thinking well of other families), norms of reciprocity (e.g., when individuals and families tend to return favours), collective action (e.g., community members are willing to get together to work for common causes), and participation (e.g., the willingness to volunteer for and participate in community activities).

Networks are understood as "structures of recurrent transactions" (Aldrich, 1982) and are described according to their inclusiveness (e.g., how welcoming groups are of newcomers and the degree of exchange of information with newcomers), diversity (e.g., the co-existence of a number of different networks of individuals or families that are capable of interacting in meaningful ways), and flexibility (e.g., the degree to which networks individuals or families can adapt to new, different, or changing needs).

The first level of the framework (the distinction between three dimensions of bonding, bridging, and linking) captures the social reality of Aboriginal communities in terms of their intra and intercommunity and institutional interactions. Social capital, understood as a relational resource, cannot truly characterize a community if it only captures within community interactions. Communities do not exist in isolation and their potential stocks of social capital must express this reality because, as Woolcock (1999) indicates, "different combinations of these dimensions might yield different outcomes."

\begin{tabular}{|llr|}
\hline \multicolumn{3}{c}{ Table 1: Social Capital Framework } \\
Bonding & Networks & \\
SIR* Ethos & Trust & Inclusive \\
\hline Physical & Norms of Reciprocity & Flexibility \\
Symbolic & Collective Action & Diverse \\
Financial & Participation & \\
Human & & \\
Natural & & \\
Bridging & Networks & \\
SIR Ethos & Trust & Inclusive \\
Physical & Norms of Reciprocity & Flexibility \\
Symbolic & Collective Action & Diverse \\
Financial & Participation & \\
Human & & \\
Natural & & \\
Linking & & Inclusive \\
SIR Ethos & Networks & Diverse \\
Physical & Trust & \\
Symbolic & Norms of Reciprocity & \\
Financial & Collective Action & \\
Human & Participation & \\
Natural & & \\
$*$ SIR $=$ Socially Invested Resources & & \\
\hline
\end{tabular}


This three-dimensional model considers social capital as a feature of communities, with the caveat that the community of which it is a feature must be clearly delimited. Aboriginal communities in both rural and urban areas can be understood as communities of identity, of place, and of interest. It is the communities themselves that implicitly or explicitly provide the delimitation.

\section{Methodology}

This article describes a study that developed as a result of the merging of interests between the Crossing Boundaries Research Initiative and the authors of the study. The former was seeking to understand how ICT may impact Aboriginal communities, particularly in relation to social capital. The authors of the study had worked with First Nations communities in developing a social capital framework that was deemed applicable to address those research objectives. To-date no research had been conducted in Canada to assess the development and impact of ICT in Aboriginal communities. The specific research questions sought to meet the objectives in a stepwise manner. The study sought to address the following three questions in relation to Aboriginal communities in Canada: Can social capital be a useful notion in assessing the impact of ICT? How can ICT impact the community social capital? Does the type of ICT development matter in terms of social capital? Figure 1 suggests the direction of the second and third questions. While Putnam (2000) addressed these questions in relation to American society, his findings may not necessarily apply to Canadian Aboriginal communities.

$$
\text { BSC=Bonding Social Capital; BrSC=Bridging Social Capital; LSC=Linking Social Capital }
$$

Figure 1. Direction of Research Questions

Given the need to address the research questions within specific Aboriginal contexts and regions of the country, the researchers chose to use a case study design. Case study design has been defined as "an empirical inquiry that: a) investigates a contemporary phenomenon within its real-life context, $b$ ) the boundaries between the phenomenon and context are not clearly evident, and c) multiple sources of evidence are used" (Yin, 1991). Case study methodology must meet the scientific standards of validity and reliability. Validity was satisfied in our study by using multiple sources of evidence, maintaining an accurate and transparent record of the data collection process, and providing for the participation of case study stakeholders in discussing the initial findings through on-site roundtables and a final symposium.

The initial set of criteria for selecting the cases was that at least one First Nations, Inuit and Métis organization be represented. Further, that there be at least one urban case. Finally, that as much as possible, that the cases be located in different regions of the country. A series of searches were conducted to locate Aboriginal ICT initiatives in Canada. As the ICT initiatives were pre-selected the researchers contacted the project directors by telephone to discuss the study and assess their interest in participating. Following the initial contact, a semi-structured telephone interview was conducted. Telephone interviews were held not only with individuals involved in Aboriginal ICT projects at the grassroots level but also with individual stakeholders from the provincial and federal levels of government. After completing 15 telephone interviews the final case studies were selected based on the scope of the project, the stage of their project, and the interest in participating. Once the five case studies were selected, we scheduled the site visits and roundtables.

The research team drafted an initial document to guide the roundtable discussions. Twenty individuals from Aboriginal organizations, government agencies, and university units with experience 
in this area provided feedback to this initial document. The five roundtables were held at the site of each case study: Sioux Lookout, Ontario (K-net); Cranbrook, British Columbia (Ktunaxa); Iqaluit, Nunavut (Qiniq); Edmonton, Alberta (Métis settlements); and Winnipeg, Manitoba (urban Aboriginal agencies). The roundtables counted between 9 and 11 participants each, excluding the research team. During the days of the roundtables, the research team conducted site visits of each initiative.

As part of the data collection process, the authors conducted an extensive review of the published and grey literature on social capital and on ICT implementation in Canada with a focus on Aboriginal communities. Further, we completed 15 semi-structured interviews with key informants from First Nations, Métis and Inuit communities and institutions in Canada. The interview guides were designed to operationalize the research questions. Nonetheless, the style of interview allowed for flexibility in the topics covered. Extensive notes by at least two researchers were taken during the interviews and later transcribed into electronic files. The two other sources of data were the published and unpublished documentation produced by the ICT initiatives, and notes from on-site observations that the researchers took during each visit (each visit lasted on average two full days).

The social capital framework previously discussed guided the analysis of the data for the case studies. Within each case study and across the five cases we coded themes relevant to different components of the framework as they related to the impact of ICT on communities and the particular characteristics of the ICT development. The interviews and roundtable discussion transcripts, as well as case documentation, were analyzed using content analysis in which key themes were identified. The case summary of each group involved content analysis and later stakeholder verification through which those who participated in the site visits were able to provide feedback on the written case summaries and have their feedback incorporated into the paper. The data was triangulated across the different sources and was further analyzed against the social capital framework.

After the data analysis was completed a final discussion paper was drafted. The research team invited representatives from the five case studies, as well as other Aboriginal and government stakeholders to participate in a symposium in Winnipeg and discuss the final report of the study. The one-day national symposium was held on January 25, 2008, in Winnipeg, Manitoba, with the participation of $23 \mathrm{key}$ stakeholders, experts and practitioners from Aboriginal organizations, and other relevant entities, to discuss the document, provide final feedback, and identify priority issues.

In terms of limitations, the study design and data available provided evidence for the inference of plausible impacts of ICT on community social capital. Nonetheless, the study design did not allow for before-and-after data analyses to empirically assess actual impacts of the initiatives. Despite this limitation, the study was fruitful in providing an understanding of the plausible mechanisms at play, both for successful community ICT implementations and in describing how the use of ICT may affect communities. Further, the study suggested that the social capital framework used by the study can be a useful theoretical model for the purpose of analyzing community ICT initiatives. It extended Putnams' (2000) examination of the issue to Canadian Aboriginal communities. Further studies by the research team will continue to refine the theoretical model, seeking to increase its capability of explanation. 


\section{Community Networks Studied}

\section{K-Net (Ontario)}

K-Net (the Kuh-ke-nah Network) in northwestern Ontario is an Aboriginal owned community ICT network that provides access to the Internet in a sparsely populated region that consists of approximately one person per square kilometre. Many communities in this region are only accessible by small aircraft and most do not have year round road access. The populations of the communities range between 300 and 900 residents.

K-Net was initially conceived as a bulletin board system (BBS) to provide support from family and friends via text messaging to children who were living away from the community to complete their schooling. The service was quickly picked up by schools and additional communities in the region and later expanded to offer broadband Internet and ICT services to communities. K-Net is currently part of the Northern Indigenous Community Satellite Network (NICSN) with the Kativik Regional Government in Quebec, and the Keewatin Tribal Council in Manitoba. Infrastructure Canada has announced funding for the NICSN project that will extend K-Net services to residents in 43 northern communities.

To date, K-Net has successfully engaged in Telehealth, innovative distance education, computer training and skills development for community members and community networking. Additionally, K-Net facilitates multipoint videoconferencing and quality of service for counterpart networks in British Columbia, Alberta, Saskatchewan, Manitoba, Quebec, and the Maritimes (Fiser, Clement, \& Walmark, 2005).

\section{Métis Connectivity (Alberta)}

Alberta was the only province in Canada to enter into a formal partnership with a Métis organization, establishing "the only form of Métis government in Canada" (Métis Settlements General Council, 2006). The Métis Nation of Alberta (MNA) was subsequently created to "advocate on behalf of and meet the needs and aspirations of Métis people in Alberta" (Métis Nation of Alberta, 2007). The MNA has recently (2006) connected their 17 provincial offices via high speed fibre optic infrastructure.

The Métis communities in Alberta differ in relation to connectivity, adoption of technology, and so on. The money available to fund connectivity projects also differs substantially by community. Alberta's SuperNet is a high speed broadband network that has the ability to connect 429 communities across the province. It was completed in July of 2004 and connects 4,200 learning and health facilities and governments' offices (Government of Alberta, 2005). SuperNet has enabled people living in rural areas to benefit from the same opportunities enjoyed by those living in urban centres (Bell Canada, 2003). However, not all Métis communities have benefited from this infrastructure.

Smaller Métis communities were not interested in having access to the SuperNet due to the cost of activating or "lighting-up" a point of presence (refers to a node or site where customers can connect into the backbone network) coupled with the cost of maintenance and administration. For some communities the overhead cost was too large an amount to take from their monthly operating budget. On the other hand, some communities have made the decision to bear the cost and become involved.

\section{Qiniq (Nunavut)}

The Qiniq network in Nunavut provides high speed Internet services to 25 Inuit communities in Nunavut. The deployment of broadband in Nunavut required a unique solution as the geography 
of the region makes it impossible to develop the basic backbone infrastructure utilized for these purposes in the south. In Nunavut there are "no highways, no power or phone lines, no fibre optic networks, and no microwave relays linking communities" and the most common method of supplying communities with goods is air or barge (Qiniq, 2005).

The Nunavut Broadband Development Corporation (NBDC) was formed as a non-profit organization interested in establishing Internet services in Nunavut communities and consisted of Nunavut government officials, Inuit organizations, and private sector companies. It was able to secure funding from Industry Canada and INAC. The initial funding enabled the NBDC to produce the business case for broadband in Nunavut and was also used to develop infrastructure. The total cost to build the Nunavut network was $\$ 9$ million of which Industry Canada's BRAND program contributed $\$ 3.4$ million. The network is called Qiniq and today Nunavut residents have an affordable broadband network.

In every Nunavut community one local person received training and is able to install wireless modems, handle basic troubleshooting, and involve people in the initiative. This person is called a community service provider. Involving local people was seen as one of the key factors in achieving success. As of 2007, one quarter of all Internet subscribers, approximately 3600 people or $12 \%$ of the population in Nunavut had subscribed and were using the Qiniq network.

\section{Ktunaxa Nation Network (British Columbia)}

The Ktunaxa Nation Broadband Network is located in south eastern British Columbia. The network area is approximately 17,871 square kilometres in size and includes 13,989 people, 8602 dwellings, 182 businesses, 5 band locations, and 58 unincorporated communities (Ktunaxa Nation, 2005). The network was initially conceived as a means through which to disseminate the disappearing Ktunaxa language, of which there are approximately 30 speakers left. Ktunaxa Nation applied for funding with Industry Canada's BRAND program and was awarded \$3.8 million.

The Ktunaxa Nation has recently been selected as a model community network for the Fully Integrated Technological (FIT) community program. In essence, Ktunaxa will receive in-kind support from the First Nation's Technology Council (FNTC) of British Columbia and in return will document their experiences in order to provide a successful model and best practice for other communities to follow. The Ktunaxa Nation Broadband project has fully utilized the FirstVoices initiative which "is a suite of web-based tools and services designed to support Aboriginal people engaged in language archiving, language teaching, and cultural revitalization" (First People's Cultural Foundation, 2003). In February of 2008, two of four planned community learning centers (CLCs) were opened in the Ktunaxa Nation communities as a result of a partnership with the University of British Columbia (Slonowski, 2008).

\section{Urban Aboriginal Initiatives (Winnipeg, Manitoba)}

The issue of access to ICT in urban centres is not based on lack of infrastructure as is the case in rural areas. Urban centres in Canada are, for the most part, well equipped with connectivity infrastructure. In urban centres, access to the Internet and computers can be seen as a function of income or the ability to purchase a computer, the necessary software, and a connection to the Internet.

In Winnipeg, under the project name LearningCiti, wireless corridors have been created in several central locations to provide free wireless Internet services in high traffic and sometimes low income areas. LearningCiti operated in conjunction with another program called the Computer Lending Library, which is an educational digital information literacy program aimed to increase the technological skills of new immigrants, Aboriginal people, and others. 
The program "Computers for Schools" in Winnipeg was initially created to provide computers to schools in Winnipeg and technological training for young people. The program also assists in facilitating the recycling of computers and other computer equipment. The Wiichiwakanak Learning Centre provides culturally relevant programs to Aboriginals in Winnipeg and has also integrated the use of computers and technology into their programming. The centre has 20 computers, Cree language courses, and a homework program.

\section{A Social Capital Analysis}

\section{Impact of ICT on Social Capital}

ICT in Aboriginal communities, although changing at a rapid pace, is still a relatively new phenomenon in its more recent development. The introduction of the Internet and broadband connectivity is the watershed innovation through which we can expect a significant impact of ICT in communities, and it has taken place at a differing pace across Canada. Nonetheless, the digital divide and digital inequality are still very much in existence. If the digital divide is properly addressed, the next five to ten years will see a dramatic increase in connectivity in the majority of Aboriginal communities. We should not forget that impact from a social well-being perspective can be understood as positive and negative. The main issue to consider is if ICT will become a tool for the enhancement of Aboriginal people's lives.

Empirical evidence that would allow for an assessment of this type is still almost non-existent. Nonetheless, the social capital framework enabled the study to consider the plausibility of the impact of ICT on communities. It can provide guidance in terms of issues to consider in the current implementation of ICT initiatives and in the formulation of areas for evaluation and research. For instance, what are the possible mechanisms through which ICT can impact the relations within communities, between communities, and across communities and formal institutions? This falls in line with Putnam's (2000) findings that ICT may be a tool for strengthening social capital. Specifically to our social capital framework, how can ICT be a tool in strengthening communities' resources, networks and ethos?

The importance of preserving language cannot be overemphasized. One of the central tenets of colonization was the taking of land and the destruction of language and traditional practices, for example through residential schools, the outlawing of potlatches, etc. Aboriginal identity is grounded in land and language. There is sufficient evidence suggesting how their loss has undermined Aboriginal communities leading to tragic consequences. It is thus revealing that some connectivity initiatives have been spearheaded precisely by the aspiration to recover and preserve language and land.

The effort of recording elders and digitalizing previous recordings, of creating a variety of online tools for teaching the language, is an investment in essential symbolic resources. It serves to enrich each community as well as the binds across communities of the same cultural ancestry. The process of collecting and using data about the land and water by Aboriginal organizations or communities, facilitated by GIS mapping capabilities, is both a symbolic and a natural resource type of investment. The return is enhanced capabilities for land claim negotiations, more informed management of the natural resources, and the use of further means to protect the land. The use of ICT is only one aspect in this process, but it is a tool that helps to galvanize interest and resources. The Inuit's creation of Unicode font for Inuktitut syllabics enables users to create their own documents and web-pages in Inuktitut as well as print out an Inuktitut keyboard layout.

The creation of community-owned Internet Service Providers (ISP) implies a financial, physical, and human investment within the community. This can be seen in a number of First Nations and in Inuit communities. The latter have very appropriately called them "community service provid- 
ers." Aside from the benefits of increased connectivity, community ISPs have the potential to become a source of income and community re-investment. Similarly, the case with enTel (the Aboriginal-owned telecommunications company in $\mathrm{BC}$ ) has the potential of return in a number of ways, increased economic development, employment, and capacity building within and across First Nations communities among others.

Telehealth, essentially a linking social capital type of resource, also has specific bonding employment spin offs. Telehealth requires positions like Telehealth coordinators, project managers, and technicians. As well, it can increase local capabilities for training in health related occupations. In general, better connectivity infrastructure can lead to more technical support positions and job-related training opportunities for young people. The fact that numerous health care providers, particularly specialists, have supported Telehealth speaks of its linking role.

ICT investments in remote communities dramatically increase their bridging and linking opportunities, with potentially major returns in business opportunities, education, and health. Simply being able to track and send out more reliable information faster when there are environmental degradations suggests increased bridging and linking capabilities to preserve natural resources.

The First Nations Technology Council (FNTC) of BC clearly demonstrates bridging social capital as it relates to supporting the development of ICT in First Nations' communities. It also provides, together with First Nations political entities, increased linking social capital vis-à-vis the government. With an original mandate to develop a technology plan that would address broadband connectivity, technical support and technical capacity building, it consequently added the mandate of using technology to promote the revitalization of culture and language. One of its most significant achievements is the Fully Integrated Technology (FIT) community model as a strategy to obtain investments.

The value of bandwidth is greatest in remote communities, and consequently from a socioeconomic perspective its potential for return is very high. The notion of socially invested resources clarifies this potential. This idea is difficult to grasp from a private for-profit business perspective, i.e., where the return is essentially measured by the profit of the company. However, from a broader perspective of community return, the potential of ICT with high capabilities can directly enhance the development of communities' business opportunities, as well as of their educational and health systems among others. A business case can be made from a narrow perspective or from a broader (and more real) perspective. The notion of social capital, where the bonding, bridging and linking dimensions are considered, can provide guidance towards the development of measures of true returns in the investment, and not simply of narrowly conceived returns.

The social capital framework also focuses on less tangible aspects of communities. The notion of ethos seeks to capture how ICT may impact features such as participation, collective action, norms of reciprocity and trust, within communities, across communities and with institutions. For this analysis it is important to distinguish different ways of utilizing ICT. For instance, videoconferencing can sometimes be used through video cameras in individual's homes. However, a common use is related to group activities such as classes, assemblies, and so on. Different modes of utilization may have differing impacts on social relations.

Some have argued that there are potential negative impacts of ICT. Increased connectivity, while facilitating interaction with the medium itself, may sacrifice everyday contact with people living nearby. Some scholars have examined whether virtual communities affect face-to-face communities (Blanchard, 2004) and have argued that because virtual communities are not completely placeless, virtual communities may even help connect people in face-to-face communities around particular topics. Numerous studies across the world have been examining the impact of online capabilities on human and social behaviour. Increased isolation within the family, addictive behaviours, and access by children to harmful material, among others issues, have been recorded. 
Although much of this is not new per se (similar critiques have been made of other media like television), the concern is that increased connectivity can augment the harm. Particularly to what we are examining, a point could be made that if Internet access will glue people to the screens, it may as a consequence decrease their participation in local community activities. Another possibility would be that positive norms of reciprocity may be eroded. Ultimately, the potential for increased individual isolation and decreased trust among community members have been raised as concerns. Some First Nations chiefs have mentioned their concern that a sudden increase in ICT capabilities may to some degree open "Pandora's box" in their communities, and one particular risk is that people may become more insular within the community.

The flip side suggests favourable impacts. Online discussion groups, within and across communities, is a simple example of participation. These online groups can facilitate people's involvement in a number of activities that, particularly in remote communities, may not have been possible before. Online discussions can also galvanize involvement and support for collective action initiatives. Videoconferencing and other online capabilities that enable group activities such as classes would in fact be encouraging participation. Even initiatives such as Telehealth, if implemented with a community development model around it, can facilitate participation and collective action in health related activities. For instance, informed debates around particular health issues, determinants of health, input in health research activities and dissemination of results, and more community involvement in health related initiatives can be facilitated with such a model of Telehealth. Telehealth can also play a bridging role across communities. Elder sessions have taken place using videoconferencing equipment, where elders get together for lunch and see and talk with relatives they have not seen for years. Reports suggest that these particular experiences were emotionally very powerful. From a bridging social capital perspective, the increased efficiency of Tribal Council meetings, easier organization of common initiatives across communities, more ongoing communication among communities, and so on, may be interpreted as increasing possibilities for collective action, as well as trust and positive norms of reciprocity.

The fact that most communities want to have videoconferencing as a way to connect with relatives and friends in other communities, suggests their awareness of its potential impact on what we are calling bridging social capital. Setting up teleconferencing units increases bridging and linking capabilities. Particularly in northern communities where travel is very expensive, this type of medium enables agency staff from different communities to participate in joint sessions and can improve the interaction with government and private institutions located in urban centres.

Broadband Internet capabilities greatly facilitate the collection of very diverse types of information. This can be within community information such as job postings, buy and sell opportunities, community events, health centre, school, administration information, and so on. For instance, a common complaint is that job postings are not properly disseminated. If the norm is to post on the band administration's website, this concern can be dissipated. From a within community perspective, ICT can facilitate (although not ensure) more inclusive and diverse networks. Simultaneously, Internet capabilities enhance the possibilities to share and disseminate information, promote businesses, entertainment options, and so on. As well, information from other communities, Tribal Councils and Aboriginal organizations can be more readily distributed. Not to mention general information from any part of the world.

In general, the school is a good focal point for the community. Consequently, if the school has good bandwidth and equipment, community members can concentrate there for a number of activities involving videoconferencing. In some ways this can strengthen the role of the school in the community, which is important particularly in some communities where many parents rarely visit the school. When a community in northern Quebec had their Christmas concert, community members living in Ottawa were invited to join the concert at the school from the Broadband Visual Communication lab by videoconference. One year there were four people from the commu- 
nity in the lab, and there were three people in Montreal, and both were connected with the school. At the school they put the projector up against the wall showing the two additional sites and each site saw the performances. During the performance it was mainly watching but after the concert was finished there was a lot of discussion and people were greeting each other, showing the new babies, and so on. Socially it appeared to work very well. This speaks to the maintenance of community networks from a bonding and bridging perspective, as well as increasing participation. The following illustrates another instance of increased participation. Thirty two First Nations in British Columbia are involved in treaty negotiations. A practical way of letting community members know what is going on in treaty discussions is to use the community server or website. Again, this talks of the potential to impact bonding and bridging networks, as well as participation, trust and collective action.

The possibility of maintaining more connections through online capabilities with relatives and friends when community members are studying or working in urban centres can also be considered as an expression of fostering inclusive and flexible networks. Being able to do online banking, for example, can be understood from a more inclusive network aspect. This relates to linking social capital.

Online capabilities can make information networks more inclusive, for example, in relation to information about governments' support to agencies that administer grant and loan programs to help Aboriginal people access capital and market resources. This can counter the information trickling down through word of mouth via sometimes non-inclusive networks. As well, the emergence of an informal social network among technicians working with the Bulletin Board System of K-Net to pool or share knowledge illustrates an impact on inclusive and flexible bridging networks.

\section{ICT Network Implementation and its Social Capital Impact}

An examination of the third question of the study is still lacking: Does the type of ICT development matter in terms of social capital? The inspection of this issue enables us to understand more holistically the relations between ICT and Aboriginal social capital, including the political aspects (i.e., power relations) inherent to this reality.

One of the most interesting insights from the examination of the ICT initiatives is that despite the what of connectivity mattering, it is the how of connectivity that can significantly make a difference in terms of community social capital. What refers to the content of the networks, while how refers to how the networks are developed and operated. In other words, the "ownership of the means of production" (in our case the ownership of the ICT networks) clearly relates to increased community social capital at the bonding, bridging and linking levels.

K-Net, Ktunaxa, and Qiniq are powerful examples of Aboriginal organizations taking control over the what and the how by responding to the realities of the communities, and strengthening them in the process. K-Net started as a response to the need to maintain contact with the youth that left the communities to further their education, Ktunaxa was born by the concern of the loss of the traditional language, and Qiniq emerged from the vision of a practical initiative to decrease the isolation of the communities. These required strong internal (bonding) investments, well crafted bridging relations among the communities and other Aboriginal organizations, and making use of potential linking investments of government programs. Among the linking investments, the sometimes contentious, sometimes positive relations with private and public corporations played an important role. Aboriginal community networks were developed by local people to meet community needs, and in the process community capacity was created in the development of the business plans and in their actual implementation. The use of technology by individuals 
and groups and the social learning that takes place in the adoption of a new technology creates social capital. Youth are generally the first to adopt new technologies and in turn teach their parents and elders computer and Internet skills. Time spent learning new skills and connecting with people to disseminate new skills may also create social capital. For instance, in Nunavut when the Qiniq network was first launched, community service providers in each community would offer to provide information about computers and the Internet and how to use the technology and equipment. This creates connections between people who (even in small communities) may not have known each other or had a reason to connect prior to the introduction of Qiniq. It would appear that the community networks have more at stake in developing active implementers of the technology, rather than passive consumers of connectivity.

The implementation of connectivity infrastructure by private companies is essentially determined by their business cases. In other words, based on population and revenue expectations the companies predict they can or cannot profit from establishing infrastructure and providing Internet services in a community. As well, the private company model assumes minimal community involvement and training. This type of network is planned in such a way that the maintenance personnel come into the community, usually from larger urban centres, to perform maintenance or solve technical problems. However, it is costly to bring technicians to fly-in communities and generally this type of maintenance requires that the community pay for the transportation and accommodations of the technicians. High maintenance and infrastructure costs often results in a network that is non-operational. In many cases, the private company may own infrastructure not far from the community and promote the service while asking the community to pay for the last mile of connectivity. In numerous occasions Aboriginal communities have been sold substandard equipment from a private company that cannot be maintained, which resulted in network connections not being utilized because of the equipment failures. Many private companies are "fly by night" and once the money is gone from the community the company does not return to ensure it is operational. In cases such as these the communities ended up feeling "burnt" by these experiences and reluctant to try other avenues (low linking social capital).

Even government health care initiatives of ICT in Aboriginal communities were somewhat of a failure when communities and other stakeholders were not involved in their implementation. In the initial attempts to develop Telehealth in the late 1990's the equipment would be delivered into a community without consideration for training, maintenance, and updating software. Frequently, the equipment would remain locked in a closet in the health unit or school as no one knew how to use it or even how to set up the equipment. In the case where a technician was sent to set up the equipment, relevant training was not provided to community members for continued operation. Further, there was no proper training of health personnel in the community to coordinate its use, and there was no clear buy-in from health professionals in urban hospitals.

Most Aboriginal community networks are partially government subsidized. Community owned networks are run by individuals who have an understanding of the values of community members and the issues that can be addressed via the use of technology. The main problem is that the subsidies are mostly project and short-term related, creating a somewhat unstable funding environment. Qiniq was established by a non-profit organization, the Nunavut Broadband Development Corporation, and was based on a private but bandwidth subsidized model. In other words, Internet service in Nunavut is not tied to Health Canada or other anchor tenants and all 25 communities have residential connectivity readily available. K-Net is based on a services model, which means connectivity is initially provided to anchor tenants such as the health unit, the administration or band office, and the school. Anchor tenants require larger amounts of bandwidth and must pay a higher monthly amount which secures the business case for the network. This model does not initially provide residential broadband access but supplies communities with a model for the creation of a community owned network. Both Qiniq and K-Net have received funding from the 
Community Access Program (CAP) to create local access points, usually in the school or band building, for the public use of computers and connectivity. Even in urban environments, where basic connectivity infrastructure is well established, the issue of accessibility related to affordability could be addressed through community initiatives using wireless modalities. The potential to develop urban Aboriginal networks would be strong.

The study suggested how ICT community networks are actually developed and implemented plays a role in strengthening the community's social capital. This was particularly evident in the cases of K-Net, Ktunaxa, and Qiniq. This implies the consideration of power relations among Aboriginal communities and organizations, governments, and private and public corporations. Legislation that favours large private or public ICT corporations over community-based profit or non-profit entities, project-based funding sources that leave community networks at the mercy of government bureaucratic whims, public connectivity infrastructure investments particularly lacking for rural and remote areas, are all instances of power relations. In fact, these are particular aspects of the broader notion of Aboriginal self-governance.

\section{Policy and Research Priority Issues}

The above approach to understanding ICT and social capital raised a number of issues that require ongoing debate, research, and policy formulation. A first key issue is that ICT infrastructure should be considered a right. As basic infrastructure for water and sanitation are a matter of equity, and services such as postal and health care are in essence guaranteed across the vast territory of Canada. Rural and remote communities that in many cases are lacking proper bandwidth are precisely the ones with the most to benefit from adequate ICT infrastructure, particularly for economic and social development.

Another central issue is that of social enterprises and social economies. Essential to the successful implementation and positive impact of ICT in Aboriginal communities appears to be community ownership and implementation of the ICT networks. Despite private sector, crown corporations and government having an important role to play, ultimately community control is what can guarantee that the power relations linked to ICT will not derail it to the detriment of community members and organizations. As well, the private business model does not work for social enterprises such as community owned networks. Serious efforts have to be directed to adjust legislation, norms, and funding models to serve these social economies.

The role of government is crucial to the above identified issues. There are a number of aspects where government at its various levels can play a positive role. Among these are the moving away from pilot project funding to longer term program funding approaches (adequate and reliable funding); reducing the duplication and fragmentation of government departments as they relate to ICT development; increasing necessary investments in ICT infrastructure at the community level; working closer with communities; assisting in securing funding for community networks; establishing legislation that, at the very least, levels the playing field for community enterprises vis-à-vis private corporations; allocating proper bandwidth and related fees in Canada (e.g., Telesat) for community and non-profit initiatives as compared to industry and other corporations.

Among the crucial investments in ICT for Aboriginal communities is that of human resource capacity building. These investments are intimately connected to community ownership and management of the networks, to the successful uptake of the technology, and to the enhanced use of the different applications for cultural, social and economic opportunities. More so, ICT is an area where youth capacity building is of particular relevance and prospect.

Addressing the digital divide or digital inequality has significant differences if it relates to urban or rural-remote settings. Within urban environments, inequality in access to adequate connec- 
tivity relates mostly to the lack of purchasing power of the computers and network connections among urban low income Aboriginals. Programs that address this inequality need to focus on household investments and community access initiatives. In rural and remote Aboriginal communities, aside from the above mentioned issue, is that of community connectivity. These communities are unique and do not mirror the economic, social, and cultural circumstances of urban centres. ICT development and implementation has to be unanchored from the urban mindset and needs to be simultaneously re-developed from the rural and remote realities.

There is a need for further research. One essential area is that of investigating the how of implementation and development of ICT in Aboriginal communities. The role of community-owned networks, the power relations among the different players (Aboriginal organizations, private and public corporations, government) must be more rigorously studied to enhance the understanding of the dynamics at play and to adequately guide future policies, programs and community initiatives. An example would be to research best practices in community ICT development and implementation. Further, the impact of connectivity in Aboriginal communities at various levels (social, cultural, economic), requires more in-depth and empirically based studies to assist Aboriginal communities, Aboriginal organizations, and the government to better capture the effects of these new realities and better foster successful implementation, development, and further investments.

Finally, it must be emphasized that ICT is in essence about relationships at various levels, not merely about technology. Relations at the social and community level, both as a draw for its use and for the social effects it may have. Further, the increased social networking across Aboriginal communities in Canada and abroad facilitated by ICT is of remarkable significance. As well, it is about relations associated with technical knowledge, financial resources, legislation, and ownership. For Aboriginal communities to properly benefit from the ICT development they need to have comparable leverage to that of the other actors, given the power dynamics at play. In essence, ICT development in Aboriginal communities is about agency and self-determination.

\section{Acknowledgements}

The authors wish to acknowledge all the individuals that participated in the interviews, round tables and the symposium, for their generosity with time and information that they provided. We would especially like to extend our appreciation to Brian Beaton, Pauline Eugene, Don Maki, Yvonne Pratt and Lorraine Thomas for all their support. We wish to acknowledge Wendy Ross, Jason Brown, and John O'Neil for collaborating with the study. Finally, the Crossing Boundaries Research Initiative and the Social Sciences and Humanities Research Council.

\section{References}

Aldrich, H. (1982). The origins and persistence of social networks. In P.Marsden \& N. Lin (Eds.), Social structure and network analysis (pp. 281-293). Beverly Hills: Sage.

Altman, J. C. (2001). Sustainable development options on Aboriginal land: The hybrid economy of the twenty-first century. Canberra: CAEPR, Australia National University: Centre for Aboriginal Economic Policy Research.

Barlow, J. P., Birkets, S., Kelly, K., \& Slouka, M. (1995, August). What are we doing online? Harper's 291, pp. 35-46.

Bell Canada. (2003). Building the Alberta SuperNet. Retrieved July 26, 2006, from http://www.albertasupernet.ca

Blanchard, A. (2004). Dispersed virtual communities and face--to--face social capital. In M. Huysman \& V. Wulf (Eds.), Social capital and information technology. Cambridge: The MIT Press. 
Impact of Information and Communication Technology

Bolin, K., Lindgren, B., Lindström, M., \& Nystedt, P. (2003). Investments in social capital--Implications of social interactions for the production of health. Social Science and Medicine, 56, 2379-2390.

Bourdieu, P. (1983). The forms of capital. In J.Richardson (Ed.), Handbook of theory and research for the sociology of education (pp. 241-258). New York: Greenwood Press.

Bourdieu, P., \& Wacquant, J. D. (1992). An invitation to reflexive sociology. Chicago: The University of Chicago Press.

Campbell, C., Williams, B., \& Gilgen, D. (2002). Is social capital a useful conceptual tool for exploring community level influences on HIV infection? An exploratory case study from South Africa. AIDS Care, 14, 41-54.

Casey, T., \& Christ, K. (2005). Social capital and economic performance in the American states. Social Science Quarterly, 86, 826-845.

Chen, W., Boase, J., \& Wellman, B. (2002). The global villagers: Comparing Internet users and uses around the world. In B. Wellman \& C. Haythornthwaite (Eds.), Internet in everyday life. Oxford: Blackwell.

Coleman, J. S. (1988). Social capital in the creation of human capital. American Journal of Sociology, 94, S95-S120.

Coleman, J. S. (1990). Foundations of social theory. Cambridge: The Belknap Press of Harvard University Press.

Dale, A. (2005). Social capital and sustainable community development: Is there a relationship? In A. Dale \& J. Onyx (Eds.), A dynamic balance: Social capital and sustainable community development. Vancouver: UBC Press.

Daly, A. (2005). Bridging the digital divide: The role of community online access centres in indigenous communities. The Centre for Aboriginal Economic Policy Research (CAEPR). Retrieved August 1, 2006, from http://dspace.anu.edu.au/handle/1885/43177

Department of Economics, U of A. (1999). 1999 creation and returns of social capital: Social networks in education and labour markets. Conference proceedings: University of Amsterdam.

Fawcett, S. B., Francisco, V. T., \& Schultz, J. A. (2000). The community tool box: A web-based resource for building healthier communities. Public Health Reports, 115(2-3), 274-278.

Fevre, R. (2000). Socializing social capital: Identity, the transition to work, and economic development. In S. Baron, J. Field, \& T. Schuller (Eds.), Social capital: Critical perspectives (pp. 94-110). Oxford: Oxford University Press.

First People's Cultural Foundation. (2003). FirstVoices. Retrieved August 1, 2006, from http://www.firstvoices.ca/scripts/WebObjects.exe/FirstVoices.woa/wa/file

Fiser, A., Clement, A., \& Walmark, B. (2005). The K--Net Development Process: A model for First Nations Broadband Community Networks. Presented at the Telecommunications Conference (TPRC) September 23-25, 2005, held at George Mason University School of Law in Arlington, VA.

Gooden, B. I. (1998). Social capital, stress and the health of rural African--Americans in central Virginia. Doctoral Dissertation. The University of North Carolina at Chapel Hill: North Carolina, USA.

Government of Alberta. (2005). Alberta SuperNet now operational throughout the province: Province marks key completion milestone during the Centennial year. Retrieved July 26, 2006, from http://www.gov.ab.ca/acn/200509/18828F93E02E6-F2D6-4F55-99D3CC5C2E0424EF.html

Hunter, B. (2000). Social exclusion, social capital, and indigenous Australians: Measuring the social costs of unemployment. Centre for Aboriginal Economic Policy Research. Discussion Paper No. 204/2000. Canberra: CAEPR, Australian National University.

Huysman M., \& Wulf, V. (2004). Social capital and information technology. Cambridge: The MIT Press. 
Kawachi, I., Kennedy, B. P., Lochner, K., \& Prothrow-Stith, D. (1997). Social capital, income inequality, and mortality. American Journal of Public Health, 87, 1491-1498.

Ktunaxa Nation. (2005). Ktunaxa Nation Network. Retrieved October 11, 2006, from http://www.ktunaxa.org/network/index.html

Levitte, Y. (2004). Bonding social capital in entrepreneurial developing communities--Survival networks or barriers? Journal of the Community Development Society, 35, 44-64.

Lin, N. (2001). Social capital: A theory of social structure and action. Cambridge, UK: Cambridge University Press.

Loury, G. C. (1992). The economics of discrimination: Getting to the core of the problem. Harvard Journal of African American Public Policy, 1, 91-110.

Métis Nation of Alberta. (2007). Métis Nation of Alberta. Retrieved October 3, 2007, from http://www.albertametis.com/MNAHome/MNA2.aspx

Métis Settlements General Council. (2006). Legislation and Policies. Retrieved October 11, 2006, from http://www.msgc.ca/main.php?page=about_legislation

Midgley, J., \& Livermore, M. (1998). Social capital and local economic development: Implications for community social work practice. Journal of Community Practice, 5, 29-40.

Mignone, J. (2003a). Measuring social capital: A guide for First Nations communities. Ottawa, Ontario: Canadian Institute for Health Information.

Mignone, J. (2003b). Social capital in First Nations communities: Conceptual development and instrument validation. Doctoral dissertation. University of Manitoba: Winnipeg.

Mignone, J., Longclaws, J., O’Neil, J., \& Mustard, C. (2004). Social capital in First Nations communities: Concept and measurement. In J. White, P. Maxim, \& D. Beavon (Eds.), Aboriginal policy research: Setting the agenda for change (pp. 125-139). Ottawa: Thompson Educational Publishing.

Mignone J., \& O’Neil, J. (2005). Conceptual understanding of social capital in First Nations communities: An illustrative description. Pimatisiwin: A Journal of Aboriginal and Indigenous Community Health, $3(2), 7-44$.

Moody, L., \& Cordua-von Specht, I. (2005). Stones: Social capital in Canadian Aboriginal communities. In A. Dale \& J. Onyx (Eds.), A dynamic balance. Vancouver: UBC Press.

Narayan, D. (1999). Bonds and bridges: Social capital and poverty. Washington, DC: The World Bank.

Nie, N. H. (2001). Sociability, interpersonal relations, and the Internet: Reconciling conflicting findings. American Behavioral Scientist, 45(3), 426-437.

Nie, N. H., Hillygus, D. S., \& Erbring, L. (2002). Internet use, interpersonal relations, and sociability: A time diary study. In B. Wellman \& C. Haythornthwaite (Eds.), Internet in everyday life. Oxford: Blackwell.

Norris, P. (2003). Social capital and ICTs: Widening or reinforcing social networks? Paper presented at the International Forum on Social Capital for Economic Revival, Tokyo, Japan. March.

O’Neil, D. (2002). Assessing community informatics: A review of methodological approaches for evaluating community networks and community technology centers. Internet Research: Electronic Networking Applications and Policy, 12(1), 76-102.

Putnam, R. D. (2000). Bowling alone: The collapse and revival of American community. New York: Touchstone.

Putnam, R. D., Leonardi, R., \& Nanetti, R. Y. (1993). Making democracy work: Civic traditions in modern Italy. Princeton, New Jersey: Princeton University Press.

Qiniq. (2005). Broadband for Nunavut: From vision to reality. Retrieved October 11, 2006 from www.qiniq.com 
Impact of Information and Communication Technology

Quan-Haase, A., \& Wellman, B. (2002). Capitalizing on the Internet: Social contact, civic engagement, and sense of community. In B. Wellman \& C. Haythornthwaite (Eds.), Internet in everyday life. Oxford: Blackwell.

Quan-Haase, A., \& Wellman, B. (2004). How does the Internet affect social capital? In M. Huysman \& V. Wulf (Eds.), Social capital and information technology. Cambridge: The MIT Press.

Rankin, K. N. (2002). Social capital, microfinance, and the politics of development. Feminist Economics, $8(1), 1-24$

Rose, R. (2000). How much does social capital add to individual health? A survey study of Russians. Social Science and Medicine, 51, 1421-1435.

Ruiz, A. (2004). Broadband Internet and rural America: The role of government in providing un-served communities with advanced telecommunications services. Santa Barbara: University of California, UCDC Washington Program.

Schuller, T., Baron, S., \& Field, J. (2000). Social capital: A review and critique. In S. Baron, J. Field, \& T. Schuller (Eds.), Social capital: Critical perspectives (pp. 1-38). Oxford: Oxford University Press.

Schwab, R., \& Sutherland, D. (2001). Building indigenous learning communities. Centre for Aboriginal Economic Policy Research. Discussion Paper No. 225/2001. Canberra: CAEPR, Australian National University.

Selouani, S. A., \& Hamam, H. (2007). Social impact of broadband Internet: A case study in the Shippagan area, a rural zone in Atlantic Canada. Journal of Information, Information Technology, and Organizations, 2, 79-94. Retrieved from http://jiito.org/articles/JIITOv2p079-094Selouani74.pdf

Slonowski, G. (2008). Ktunaxa Nation research partnership launches two community learning centers. Retrieved May 1, 2008, from http://www.publicaffairs.ubc.ca/media/releases/2008/mr-08-026.html

Smith, D. E. (2001). Community participation agreements: A model for welfare reform from communitybased research. Centre for Aboriginal Economic Policy Research. Discussion Paper No. 223/2001. Canberra: CAEPR, Australian National University.

Steinmueller, W. E. (2004). ICTs and social capital. Paper presented at the DRUID Winter Conference, January.

Szreter, S. (2000). Social capital, the economy, and education in historical perspective. In S. Baron, J. Field, \& T. Schuller (Eds.), Social capital: Critical perspectives (pp. 56-77). Oxford: Oxford University Press.

Telenor, R. L. (2004). SOCQUIT: Deliverable 6: Report of literature and data review, including conceptual framework and implications for IST. Sixth Framework Programme. Retrieved June 14, 2008 from http://www.eurescom.de/soquit/SOQUIT_Publications.htm

Veenstra, G. (2000). Social capital, SES and health: An individual-level analysis. Social Science and Medicine, 50, 619-629.

Wellman, B. A., Quan-Haase, A., Witte, J., \& Hampton, K. (2001). Does the Internet increase, decrease, or supplement social capital? Social networks, participation, and community commitment. American Behavioral Scientist, 45(3), 437-456.

Woolcock, M. (1998a). Social capital and economic development: Toward a theoretical synthesis and policy framework. Theory and Society, 27, 151-208.

Woolcock, M. (1998b). Social theory, development policy, and poverty alleviation: A comparativehistorical analysis of group-based banking in developing economies. Doctoral dissertation. Sociology. Brown University.

Woolcock, M. (1999). Managing risk, shocks, and opportunity in developing economies: The role of social capital. In G. Ranis (Ed), Dimensions of development. New Haven, C T: Yale Center for International and Area Studies. 
Woolcock, M., \& Narayan, D. (2000). Social capital: Implications for development theory, research, and policy. The World Bank Research Observer, 15, 225-249.

Yin, R. K. (1991). Case study research: Design and methods. Newbury Park: Sage Publications.

\section{Biographies}

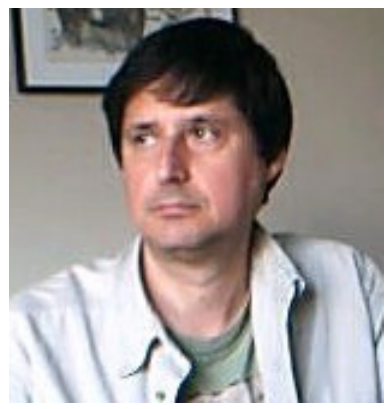

Javier Mignone is assistant professor at the Faculty of Human Ecology, The University of Manitoba. Among his recent research is the conceptual development and measurement of social capital as it applies to Aboriginal communities.

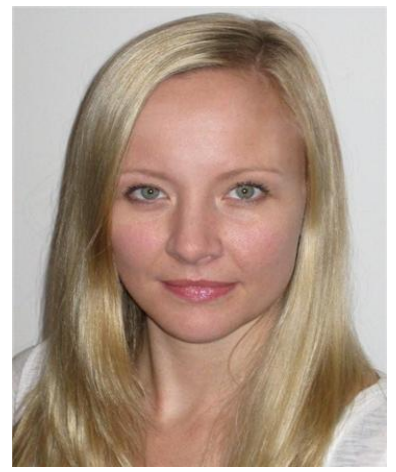

Heather Henley is currently completing a Masters degree in Natural Resources Management at the University of Manitoba in Winnipeg, Manitoba, Canada. Her thesis examines the use of ICTs in relation to land and language in the Ktunaxa First Nation communities in British Columbia, Canada. Heather completed an honours degree in Sociology at the University of Manitoba in 2005. 